\title{
Sensitivity Analysis for Performance and Power Density Improvements in Salient-Pole Synchronous Generators
}

\author{
Yinli Wang, Gaurang Vakil, Stefano Nuzzo, Michele Degano, Michael Galea, Chris Gerada, He Zhang and \\ Neil Brown
}

\begin{abstract}
Objective of this paper is to provide design recommendations to improve the performance and power density of a 400kVA salient-pole synchronous generator, without exceeding the limitations due to critical parameters such as total harmonic distortion of the no-load voltage. Preliminarily, a finite-element analysis of the considered machine is carried out, aiming at validating the inherent model against experiment measurements. An in-detailed sensitivity analysis of the machine's design parameters that mostly affect the performance of the platform under investigation is performed. It has been found that the position and the shape of axial ventilation ducts, as well as the stator slot shape do not affect the electromagnetic performance in a significant way and it can be highly beneficial from a thermal point of view, resulting in reduced rotor temperatures. Additionally, the shape of the salient poles and the damper winding arrangement can produce positive effects on the general performance, particularly allowing for an improved voltage THD and power density of the machine being studied in this paper.
\end{abstract}

Index Terms-Salient-Pole Synchronous Generator, Power Density, Total Harmonic Distortion.

\section{INTRODUCTION}

$\mathrm{W}$ OUND field salient-pole synchronous generators (SGs) have been proved to be a reliable and efficient power generation source [1]. High demands for higher power density and efficiency leads to more research effort to be spent on these extensively studied classical machines.

Being such a consolidated technology, many power density and efficiency improvements options have been proposed in literature. In this context, several aspects such as the thermal management, different winding configurations, the rotor pole shape and the damper cage topology have been widely considered. It is well known that the thermal performance of an electric machine has a great effect on the insulation material's life time [2] and the overall efficiency. Therefore, reduced temperature or increased cooling could result in better performance and higher power density [3].

Stator winding configuration can have a significant effect on the magnitude of the fundamental harmonic of the output voltage and its higher order harmonics. For example, twothird short pitching cancels the triplen harmonics, however, at cost of significantly reducing the fundamental voltage. On the other hand, five-sixth short pitching attenuates $5^{\text {th }}$ and $7^{\text {th }}$

Y. Wang, G. Vakil, S. Nuzzo, M. Degano, M. Galea, C. Gerada, H. Zhang are with the Power Electronics, Machine Drives and Control Group, Department of Electrical Engineering University of Nottingham, Nottingham, UK; e-mail: Yinli.Wang@ nottingham.edu.cn

Y. Wang, M. Dergano, C. Gerada, H. Zhang are with Power Electronics, Machine Drives and Control Group, Department of Electrical Engineering University of Nottingham, Ningbo, China; e-mail: Yinli.Wang@nottingham.edu.cn

N. Brown is with Cummins Power Generation, Peterborough, UK; email: neil.brown@cummins.com. harmonics, without resulting in a significant reduction of the output voltage [4]. Some strategies for winding configuration has been proposed such as a combined concentrated and overlapped winding structure. [5]. This winding configuration helps to reduce the space harmonic contents presented in the airgap flux density.

The geometry of the stator slots and rotor poles can also affect the performance of electrical machines. The flux lines distribution can be modified and the hysteresis and eddy current losses can be significantly varied. In [6], the geometry of the stator slots has been optimized to achieve the optimum torque production while achieving the minimum amount of losses possible. In addition, the geometry of rotor poles also influences the airgap flux density. In fact, by optimizing the shape of salient poles, harmonic content of airgap flux density can be strongly reduced at a cost of an increased leakage flux [4]. All these methods can be considered as options to increase both power density and efficiency of the SG being studied in this paper.

In addition to the method presented above, the damper winding design has been proved to be of a great effect on the overall performance of SGs [7]. The THD of the no-load output voltage can be improved by appropriately designing this additional rotor winding [8]. Currents and inherent losses can be induced in the damper bars, especially in large SGs where the stator core is typically featured with an openslot structure, resulting in a negative impact on the overall efficiency of this machines [9]. Conventional methods for estimating damping current includes dq equivalent circuit approach, permeance models and numerical integration method [9]-[11]. With the fast development of the computing resources, finite element method is used to analyse the effects that various damper winding configurations have on the voltage THD and associate damper bar losses. In particular, [12] shows that some damper cage features have a significant effect on the THD and the overall efficiency of a machine. A new damper winding topology is proposed in [7] aiming at reducing the damper cage losses whilst keeping the THD of the no-load voltage under acceptable limits.

It is clear from above that there is a revamped interest in renewing the design of such classical machine, making it still an ideal vessel of ongoing research. This paper therefore aims at proposing design recommendations for a $400 \mathrm{kVA}$ SG to increase its power density without compromising some of the most critical parameters such as the THD of the no-load output voltage and the overall efficiency.

\section{THE FINITE ELEMENT MODEL AND ITS VALIDATION AGAINST EXPERIMENTAL RESULTS}

The generator being studied in this paper is a four-pole 
machine designed for various power generation purposes such as oil gas, marine and standby application. This machine has a rated apparent power of 400kVA and is designed to operate at different output voltage and current levels and operating frequencies.

A detailed 2-D finite-element (FE) model of the platform is build and then validated against experiment data, when operating at $50 \mathrm{~Hz}, 0.8$ power factor and rated output voltage. A graphical description of the FE model is shown in Fig. 1.

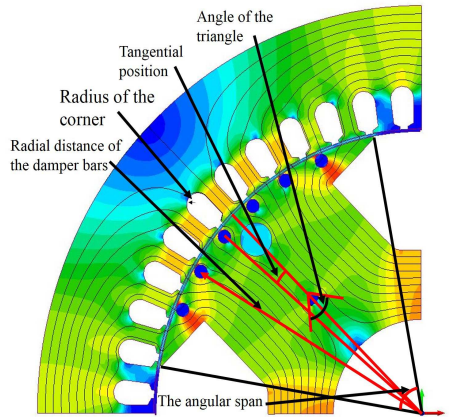

Fig. 1. Field map of the $400 \mathrm{kVA}$ alternator at no-load operation.

As shown in Fig. 1, taking advantages of all the symmetries that characterise the considered SG, only a quarter of the machine is modelled to minimise the computational time. Special focus is given to the damper cage modelling as this winding significantly affects the voltage waveform [13]. The rotor bars are connected in parallel through short-circuiting end connections. In addition, solid damper bars allow for the skin effect to be taken into consideration and thus ensures for an increased accuracy. In fact, it is important to analyse the damper bar losses as they give a qualitative indication of the thermal performance of the analysed machine.

Another major feature of the considered SG is the axial skewing which is applied to the stator core. This allows to maintain the THD of the line-to-line voltage under required standard level. In order to model this feature, the multisimulation method [14] is used, where a set of 2-D slices with appropriate shift between rotor and stator are created and then post-processed by using averaging processes.

The FE model validation exercise is described in the following sections, where the no-load and the full-load results are compared against available experimental measurements.

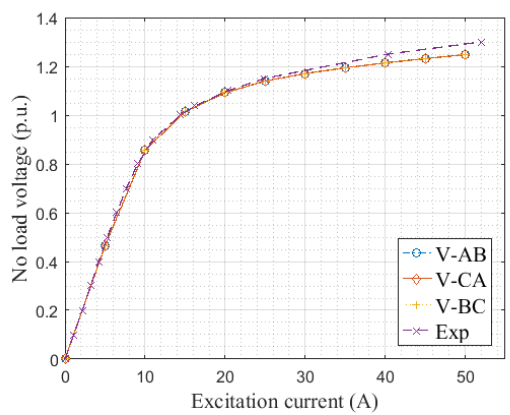

Fig. 2. No load characteristics - simulation vs. experimental results.

\section{A. Open circuit characteristics}

The open circuit characteristic is attained by measuring the voltage at the stator output terminals at different values of the rotor excitation current. Accurate simulation results are achieved by using transient with motion, as this allows to account for all the harmonic components of the output voltage. Fig. 2 compares the FE and experimental outcomes. FE results closely follow the experimental curve.

\section{B. Total harmonic distortion of output voltage}

It is of paramount importance to evaluate the THD of the output SG's voltage at no-load operation, as it indicates the quality of the voltage waveform. To reach acceptable THD values, the machine is equipped with a skewed stator. Fig. 3 shows how the FE-evaluated THD of the line-to-line voltage, (when the machine is working at no-load and the rated voltage is induced at stator terminals,) can be affected by the number of slices simulated. This sensitivity analysis shows that the THD steadies at approximately $1.3 \%$ which is very similar to the experimentally-evaluated value that is $\cong 1.5 \%$

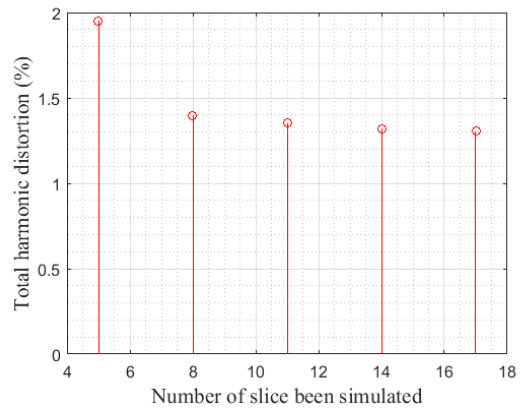

Fig. 3. Voltage THD in a skewed machine vs. number of slices.

\section{Full-load results}

The FE model described above comprises flexibility in terms of simulating different loading operating conditions. To simulate the on-load operations, circuital load resistances and inductances are used in the circuit coupled to the FE model, according to the targeted power factor, terminal voltage and apparent power.

TABLE I

Comparison of full-load output current and voltage at different power factor

\begin{tabular}{|r|r|r|r|r|}
\hline Power factor & V_simulation (V) & V_exp (V) & I_simulation (A) & I_exp (A) \\
\hline 0.8 & 402.6 & 400.0 & 579.7 & 577.4 \\
\hline 0.9 & 403.3 & 400.0 & 516.5 & 513.2 \\
\hline 1.0 & 415.5 & 400.0 & 479.9 & 461.9 \\
\hline
\end{tabular}

TABLE I shows a comparison between simulation results against experimental data regarding to full-load output voltage and current. A good agreement between simulation results and experimental data is observed, where the maximum error $(3.75 \%)$ is registered at unity power factor. It can be concluded that the FE model is validated for this machine.

\section{SENSITIVITY ANALYSIS FOR POWER DENSITY IMPROVEMENTS}

Section II has shown the validity of the FE model, achieved by comparing the simulation and experimental results. The validated model can therefore be used to perform the sensitivity analysis on the machine design parameters which mostly affect the power density. The concerned parameters that can potentially improve the machine performance from a thermal, mechanical and electromagnetic points of view include

- The position, diameter and the shape of axial ventilation ducts; 
- The angular span of rotor poles;

- The shape of rotor poles;

- The shape of stator slots;

- The tangential position of the damper bars;

- The radial distance of the damper bars from the centre of the machine.

All these aspects are investigated in the following sections, aiming at finding possible improved designs of the platform analysed in this paper.

\section{A. Improved cooling ventilation ducts}

In Fig. 1, the field map and the flux lines distribution of the considered SG at no-load condition have been shown. It can be observed that absolute value of the flux density on the rotor pole is less than that on the rotor yoke. Therefore, it may be possible to provide the rotor poles with ventilation ducts without significant impact on the electromagnetic behaviour of the machine. To reduce the simulation time, the number of slices being simulated is chosen to be 5 . Thus, as observable in Fig. 3, the voltage THD is close to $2 \%$.

First, the position and the radius of circular-shaped ventilation ducts are analysed. Fig. 4 and Fig. 6 proves that the rms line to line output voltage drop (on the y-axis) is less than $1 \%$ when the position of the ducts (on the $\mathrm{x}$-axis) is investigated. The output voltage is therefore not significantly affected by this parameter. In addition, the THD is very close to $2 \%$, as shown in Fig. 5 and Fig. 7 demonstrating again no modifications on the overall generator performance due to this parameter.

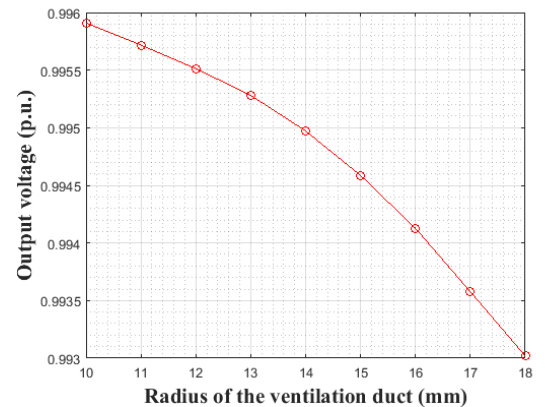

Fig. 4. Output terminal voltage vs. the radius of the ventilation duct.

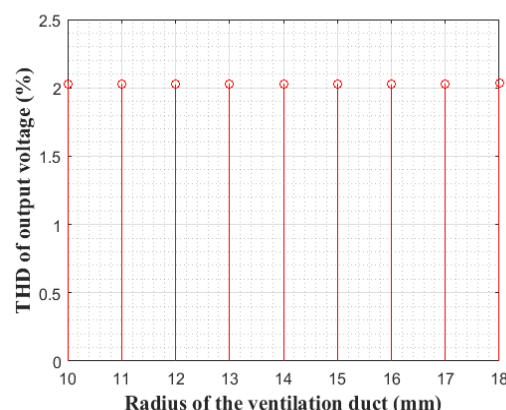

Fig. 5. THD of the output voltage vs. the radius of the ventilation duct.

Considering the results shown above, it can be safely concluded that the electromagnetic performance of the machine under investigation is not affected by the presence of extra ventilation ducts on the rotor. These ducts can potentially help to reduce the rotor temperature enabling the SG to have a higher rotor magnetic loading.

Once an optimal height and radius of the circular ventilation ducts is determined to retain mechanical integrity, a triangular shaped duct is used for the same sensitivity study purpose. This triangle is an isosceles triangle symmetrical to the centre line containing the circle analysed in the previous section.

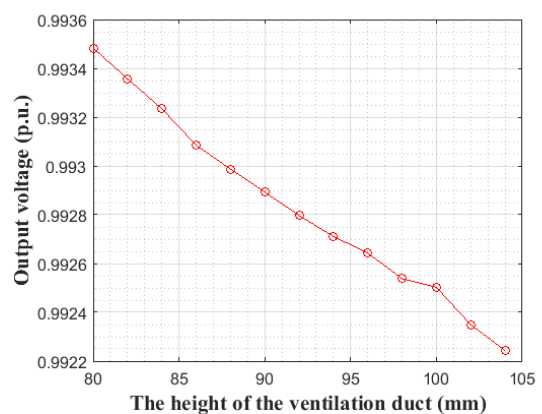

Fig. 6. Output terminal voltage vs. the height of the ventilation duct.

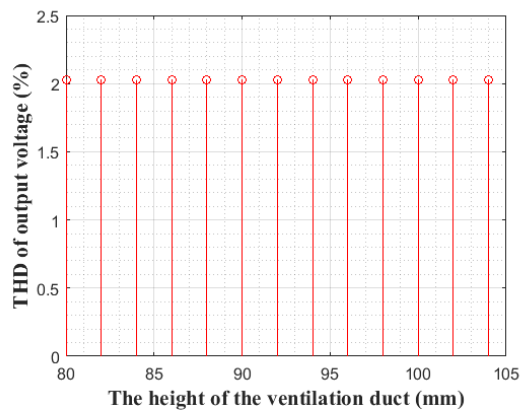

Fig. 7. THD of the output voltage vs. the height of the ventilation duct.

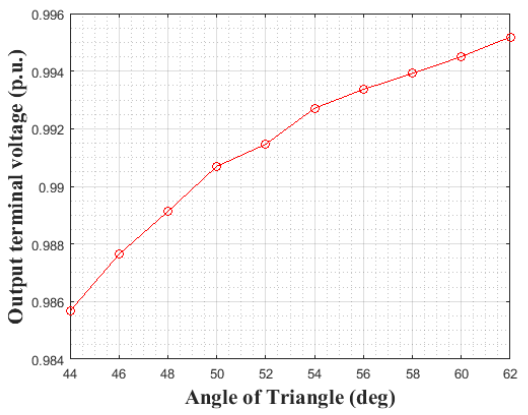

Fig. 8. Output voltage vs. angle of the top vertex of triangular duct.

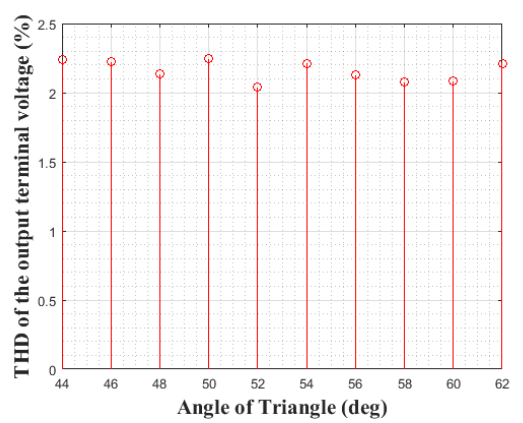

Fig. 9. THD of the output terminal voltage vs. angle of the top vertex of the triangular duct.

It is clear from Fig. 8 that the output terminal voltage is not significantly affected by altering the magnitude of the top angle of the triangular shaped duct. The maximum voltage drop is $1.4 \%$. In addition, the THD of the output voltage is slightly increased by approximately $10 \%$ compared with original design (see Fig. 3). However, the maximum THD of the output terminal voltage is still less than the required standard. Therefore, triangular shaped ducts do not have an evident impact on the THD and output voltage. In contrast, these ducts help to reduce the rotor temperature compared with circular shaped ducts since the surface area of the ducts is increased. 


\section{B. The Angular span of rotor poles}

The effect of the angular span of rotor poles is analysed in this section. Fig. 10 shows the THD variation with the angular span of the poles. It can be observed how a span of 73 degrees presents the minimum voltage THD. In correspondence of this optimal span, the output voltage is $99.8 \%$ of the rated value, as it can be seen in Fig. 11. The reduction of the voltage is therefore negligible compared with the rated voltage. This helps above results show that also the rotor angular span is an important parameter which can help to increase the power quality of the considered alternator.

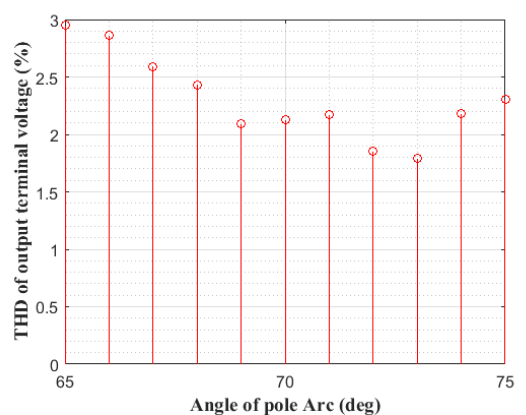

Fig. 10. Total harmonic distortion with different angular spans.

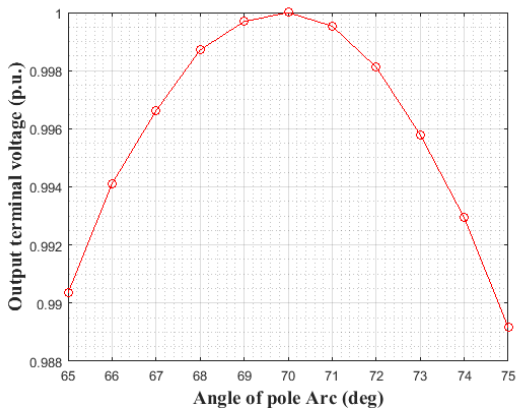

Fig. 11. RMS output line to line voltage with different angualr spans.

\section{The shape of rotor poles}

It is well-known that the airgap thickness represents the main machine parameter used by SG's designers to optimise the flux density harmonic content in the airgap. A nonuniform airgap along the salient poles for the machine under study is investigated to determine whether the third harmonic in the airgap flux density can be reduce. In fact, a third harmonic reduction would allow for a different short pitching being used in the machine and an ensuing increased output voltage.

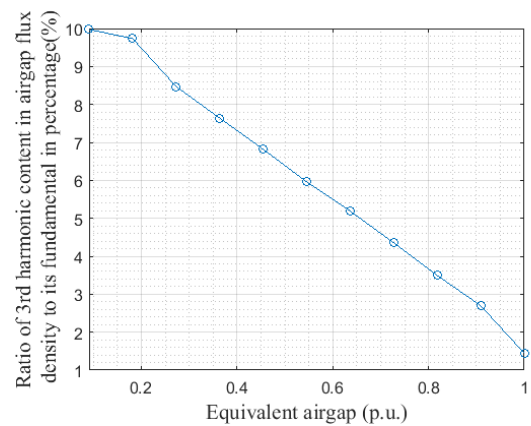

Fig. 12. Magnitude of 3rd harmonic of the airgap flux density vs. different equivalent airgap.

An equivalent airgap is defined as the mean value between the maximum and minimum airgap length. Fig. 12 shows how the third harmonic in the flux density varies by changing the equivalent airgap thickness. An increased equivalent airgap results in a lower third harmonic. This reduces the voltage THD as shown in Fig. 13. However, the reduction in third harmonic component comes at a cost of a reduction of the available output voltage at the opencircuited terminals of stator windings. This is shown in Fig. 14.

In conclusion, altering the length of the airgap is helpful with respect to decreasing the total harmonic distortion and third harmonic.

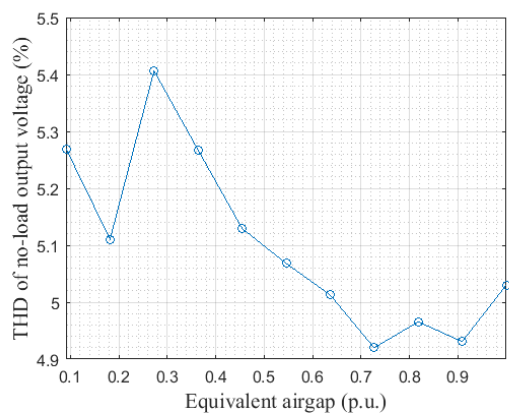

Fig. 13. Total harmonic distortion vs. equivalent airgap.

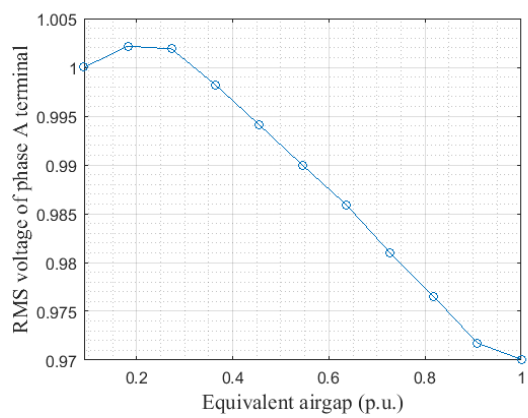

Fig. 14. RMS voltage vs. equivalent airgap.

\section{The shape of stator slots}

In this section, the effects on the overall performance of the shape of the stator slots is investigated. The radius of the slot corner (see Fig. 1) is decreased without changing the height of the stator slots.

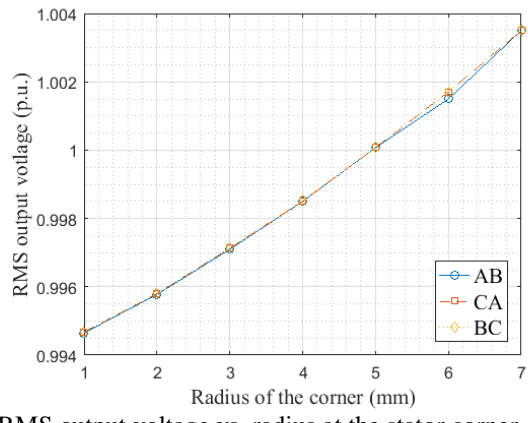

Fig. 15. RMS output voltage vs. radius at the stator corner.

It can clearly be seen in Fig. 15 that the voltage drop at output terminals is less than $1 \%$, which can be compromised by increasing the field current without significantly compromising the rotor temperature. The advantage gained by having a square stator slots is that of increasing the slot area by about $9 \%$. This allows for more conductors to be placed into the slots, which increases the effective area of copper conductor. Therefore, the overall resistance of a coil is reduced resulting in reduced stator temperatures and higher electric loading potentially applicable on the stator. 


\section{E. The tangential position of the damper bars}

The existing damper bars are symmetrically displaced over the salient poles (see Fig. 1). Previous works [15] have shown that moving the bars along the tangential direction can be beneficial for the no-load voltage waveform, however at cost of increasing the damper cage losses. Therefore, this section investigates this aspect by studying the effects that repositioning the bars have on the voltage THD and total RMS values. All the bars shown in Fig. 1 have then been moved in a uniform direction from right hand side to the left-hand side by -6 degree to 6 degree with respect to the original position. A non-skewed model is used to retain all the harmonic contents presented in the terminal voltage.

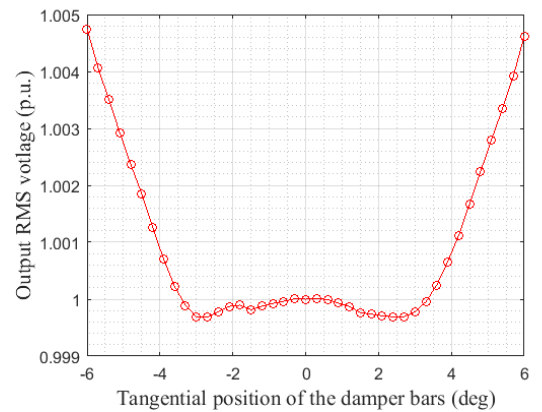

Fig. 16. RMS voltage vs. tangential position.

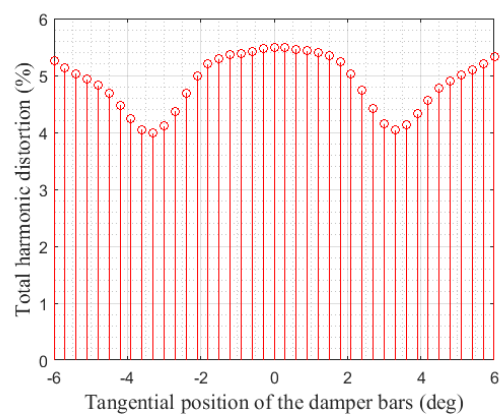

Fig. 17. Total harmonic distortion vs. tangential position.

Fig. 17 indicates that the line-to-line voltage THD can be reduced by $1.5 \%$ by moving the bars tangentially to both sides by 3.3 degrees. The THD is not accompanied by an augmentation of the output voltage, as seen in Fig. 16, meaning that no power density improvement is achievable with this technique on the considered SG.

\section{F. The radial position of the damper bars}

The depth of four damper bars placed in the middle of the poles is investigated in this section. The two bars positioned at the rotor pole tips are not moved due to the mechanical constrains. A non-skewed model is used for this analysis. The variation of output terminal voltage is less than $0.5 \%$, while the THD is significantly varying and it has its minimum value when the distance of the bars form the airgap is at its minimum. Thus, a small amount of voltage increase leads to double the voltage THD.

Therefore, modifying the depth of the damper bars does not have an impact on increasing the output voltage available at stator terminals, while it has a great sacrifice in terms of the voltage THD. Therefore, it can be concluded that moving the damper bars along the radial direction is not a good solution for increasing the power density without resorting to other compensation aspects.

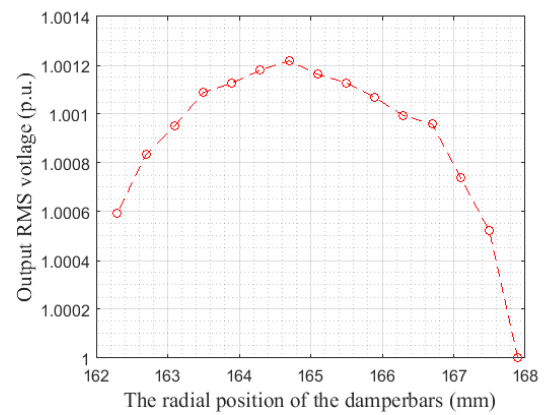

Fig. 18. RMS output voltage vs. depth of damper bars.

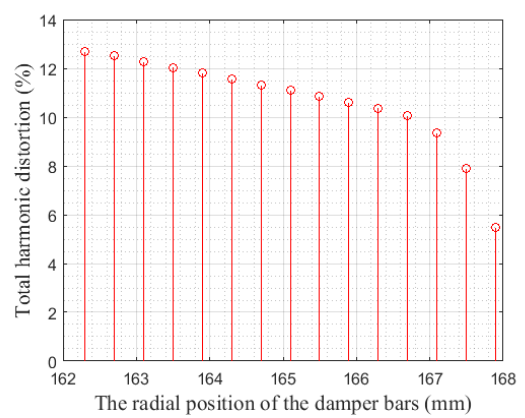

Fig. 19. Total harmonic distortion vs. damper bar depth.

\section{CONCLUSION}

The objective of this paper is to investigate and propose solutions aiming at increasing the power density of synchronous generators without compromising other parameters such as THD and the available terminal voltage. As vehicle for this study, a 400kVA SG has been considered and the following conclusions can be drawn

- Rotor ventilation ducts can improve the SG thermal performance without compromising the terminal voltage by more than $2 \%$.

- By applying a non-uniform airgap for this machine, a significant reduction of third harmonic content by $8 \%$ is observed with a $3 \%$ reduction of the terminal voltage. This can be however compromised by increasing the field current under the allowance of rotor temperature.

- Altering the tangential position of the damper bars by 3.3 degrees gives a $1.5 \%$ reduction of voltage THD. On the other hand, change in terminal voltage is $0.5 \%$ which is negligible.

- Qualitatively, the square shaped slots are shown to have insignificant effect on the terminal voltage. However, new shape of slots allows extra conductors to be arranged into the slots. This helps reduce the losses in the armature windings.

- Radial position of the damper bars does improve the THD, but seems to be ineffective for power density improvements.

\section{ACKNOWLEDGMENT}

This work is supported by the Ningbo Science and Technology Bureau, China under Grant 2014D10013. 


\section{REFERENCES}

[1] A. A. Renjit, M. S. Illindala, and D. A. Klapp, "Graphical and Analytical Methods for Stalling Analysis of Engine Generator Sets," IEEE Transactions on Industry Applications, vol. 50, pp. 2967-2975, 2014.

[2] "IEEE Guide for Insulation Maintenance of Electric Machines," IEEE Std 56-2016, pp. 1-86, 2016.

[3] P. H. Connor, S. J. Pickering, C. Gerada, C. N. Eastwick, and C. Micallef, "CFD modelling of an entire synchronous generator for improved thermal management," in 6th IET International Conference on Power Electronics, Machines and Drives (PEMD 2012), 2012, pp. 1-6.

[4] J. Pyrhonen, T. Jokinen, and V. Hrabovcova, Design of Rotating Electrical Machines (2). Somerset, GB: Wiley, 2013.

[5] M. A. Kabir and I. Husain, "New multilayer winding configuration for distributed MMF in AC machines with shorter end-turn length," in 2016 IEEE Power and Energy Society General Meeting (PESGM), 2016, pp. 1-5.

[6] A. Al-Timimy, M. Degano, P. Giangrande, G. L. Calzo, Z. X. M. Galea, C. Gerada, et al., "Design and optimization of a high power density machine for flooded industrial pump," in 2016 XXII International Conference on Electrical Machines (ICEM), 2016, pp. 1480-1486.

[7] S. Nuzzo, M. Degano, M. Galea, C. Gerada, D. Gerada, and N Brown, "Improved Damper Cage Design for Salient-Pole Synchronous Generators," IEEE Transactions on Industrial Electronics, vol. 64, pp. 1958-1970, 2017

[8] D. w. Zhang, Y. j. Peng, and Z. n. Fan, "No-Load Voltage Waveform Optimization and Rotor Heat Reduction of Tubular Hydro-Generator," in 2012 Sixth International Conference on Electromagnetic Field Problems and Applications, 2012, pp. 1-4.

[9] G. Traxler-Samek, T. Lugand, and A. Schwery, "Additional Losses in the Damper Winding of Large Hydrogenerators at Open-Circuit and Load Conditions," IEEE Transactions on Industrial Electronics, vol. 57, pp. 154-160, 2010.

[10] M. M. Liwschitz-Garik, "Harmonics of the Salient-Pole Synchronous Machine and Their Effects Part III. Differential Leakage of the Damper Winding with Respect to the Main Wave. Current Distribution in the Damper Bars," Transactions of the American Institute of Electrical Engineers. Part III: Power Apparatus and Systems, vol. 77, pp. 462-469, 1958

[11] A. M. Knight, H. Karmaker, and K. Weeber, "Use of a permeance model to predict force harmonic components and damper winding effects in salient-pole synchronous machines," IEEE Transactions on Energy Conversion, vol. 17, pp. 478-484, 2002.

[12] P. A. Hargreaves, B. C. Mecrow, and R. Hall, "Open circuit voltage distortion in salient pole synchronous generators with damper windings," in 5th IET International Conference on Power Electronics, Machines and Drives (PEMD 2010), 2010, pp. 1-6.

[13] N. Bianchi, Electrical machine analysis using finite elements / Nicola Bianchi. Boca Raton, Fla.: Boca Raton, Fla. : CRC Press, 2005

[14] S. Williamson, T. J. Flack, and A. F. Volschenk, "Representation of skew in time-stepped two-dimensional finite-element models of electrical machines," IEEE Transactions on Industry Applications, vol. 31, pp. 1009-1015, 1995.

[15] S. Nuzzo, M. Galea, C. Gerada, D. Gerada, A. Mebarki, and N. L. Brown, "Damper cage loss reduction and no-load voltage THD improvements in salient-pole synchronous generators," in 8th IET International Conference on Power Electronics, Machines and Drives (PEMD 2016), 2016, pp. 1-7.

\section{BIOGRAPHIES}

Yinli Wang received his BEng degree in Electrical and Electronic Engineering from the University of Nottingham, UK Campus in 2015. He is currently a Ph.D. student with Power Electronics, Machines and Control Group, The University of Nottingham, UK Campus and Power Electronic and Electrical Drive Research Group, The University of Nottingham, Ningbo Campus. His current research interests include the analysis and design of high performance synchronous starter generators.

Gaurang Vakil (M'16) received Ph.D. from Power Electronics, Machines and Drives (PEMD) group at Indian Institute of Technology - Delhi (IITD) in variable speed generator design for renewable energy applications in 2016. He subsequently worked as a Research Associate with Power Electronics, Machines and Controls (PEMC) group at the University of Nottingham. In 2016 he was appointed as an assistant professor with electrical and electronics engineering department in University of Nottingham. His main research interests include analytical modelling and design optimization of electrical machines, optimizing electric drive-train for pure electric and hybrid vehicles, high power density machines, magnetic material characterization and high-performance electrical machines for transport, and renewable energy applications.

Stefano Nuzzo received his B.Sc. and M.Sc. degrees in Electrical Engineering from the University of Pisa, Pisa, Italy, in 2011 and 2014, respectively. $\mathrm{He}$ is currently a $\mathrm{Ph} . \mathrm{D}$. student with the Power Electronics, Machines and Control Group, The University of Nottingham, Nottingham, U.K. He spent six months with The University of Nottingham as a Visiting Student in 2013, where he was involved in developing analytical and numerical models for the analysis of permanent magnet synchronous machines. His current research interests include the analysis and design of salient-pole synchronous generators and brushless excitation systems.

Michele Degano (M'15) received the Laurea degree in Electrical Engineering from the University of Trieste, Italy, in 2011 and the Ph.D. degree in Industrial Engineering from the University of Padova, Italy, in 2015. During his doctoral training, he has cooperated with several local companies for the design and permanent magnet machines. In 2015 he joined the Power Electronics, Machines and Control Research (PEMC) Group, University of Nottingham, U.K, as a Research Fellow. His main research interests are in the design and optimization of permanent magnet machines, reluctance and permanent-magnet-assisted synchronous reluctance motors through genetic optimization techniques, in applications ranging from small to large power. He is currently an assistant professor teaching advanced electrical machines at the University of Nottingham.

Michael Galea received his $\mathrm{PhD}$ in electrical machines design from the University of Nottingham, UK, where he has also worked as a Research Fellow. He is currently a Lecturer in Electrical Machines and Drives within the PEMC research group of the University of Nottingham. He is the Deputy Director of the Institute for Aerospace Technology at the University of Nottingham, where he is also a Lecturer in Aerospace Systems Integration and where he manages a number of diverse projects related to the more / all electric aircraft and associated fields. His main research interests are design, analysis and thermal management of electrical machines and drives and the more electric aircraft.

Chris Gerada (M'05) received the Ph.D. degree in numerical modelling of electrical machines from The University of Nottingham, Nottingham, U.K., in 2005. He subsequently worked as a Researcher with The University of Nottingham on high-performance electrical drives and on the design and modelling of electromagnetic actuators for aerospace applications. Since 2006, he has been the Project Manager of the GE Aviation Strategic Partnership. In 2008, he was appointed as a Lecturer in electrical machines; in 2011, as an Associate Professor; and in 2013, as a Professor at The University of Nottingham. His main research interests include the design and modelling of high-performance electric drives and machines. Prof. Gerada serves as an Associate Editor for the IEEE TRANSACTIONS ON INDUSTRY APPLICATIONS and is the Chair of the IEEE IES Electrical Machines Committee.

He Zhang (M'14) received his B.Eng. degree from Zhejiang University, China, in 2002. He obtained the Ph.D. degree in electrical machines from The University of Nottingham, UK, in 2009. Then he joined the UK Water Research Centre, and worked on energy efficiency determination for motor drive system for two years. He is currently a Principal Research Fellow and Director of Best motion machine drive technology centre within the Power Electronics, Machines and Control research group in University of Nottingham. His research interests include high performance electric machines and drives

Neil Brown is Chief Engineer Stamford Products, Cummins Generator Technologies. Neil joined Cummins in 1995. While at Cummins, Neil has held various roles including; Applications Engineer, Electromagnetic Design Engineer, Research Manager, Chief Engineer for Stamford Products, Chief Engineer Research and Technology, Director Advanced Electrical Machines before returning to Chief Engineer Stamford Products in 2016. Before his time at Cummins, Neil ran his own electrical business, was a college lecturer and worked for GEC on projects up to 100MVA. Neil is author of 80 publications, named inventor of 11 patents, co-inventor of the "Haydock Brown Machine", is a certified Six Sigma Green Belt and Sponsor, a Chartered Engineer and Fellow of the Institute of Engineering and Technology. Neil received a First from Nottingham Trent University in 1991, PhD from Durham University in 2003 and is presently a visiting Professor. 